\section{QUATRO DÉCADAS DE PIANO EM GRUPO NO BRASIL (1973-2013): ENTREVISTA COM MARION VERHAALEN ${ }^{1}$}

1. School Sisters of St. Francis - Doctor of Education.
Em 2013, enquanto eu desenvolvia minhas pesquisas sobre Piano em Grupo no Brasil, dei-me conta de que essa data significava exatos 40 anos da introdução do Piano em Grupo no país. Além disso, da minha curiosidade para conhecer um pouco mais sobre a chamada "pré-estória" do Piano em Grupo, mencionada por Maria de Lourdes Junqueira Gonçalves², associada à carência de fonte bibliográfica primária sobre a história do Piano em Grupo no Brasil, assim como métodos de ensino, nessa modalidade coletiva, surgiu-me a ideia de entrevistar Marion Verhaalen. Portanto, acreditei que a entrevistada norte-americana, por ser a pioneira na introdução do Piano em Grupo no nosso país, tinha informaçóes importantes para oferecer sobre metodologia de ensino de Piano em Grupo e sua introdução ao desenvolvimento dessa modalidade no Brasil.

De acordo com o relato de Marion Verhaalen, ela pertencia ao corpo docente da Alverno College na cidade de Milwaukee, estado de Winconsin, Estados Unidos da América. Marion também já havia participado de um dos primeiros workshops em ensino coletivo, que o Dr. Robert Pace ofereceu na cidade de Denver, Colorado, em 1963. Ela iniciou a organização de aulas em grupo imediatamente, utilizando o método de Pace, com seus próprios alunos menores, no Alverno's Preparatory Department. Dr. Pace providenciou um certificado a Marion Verhaalen qualificando-a como apta a adotar a prática de sua metodologia na capacitação de outros professores.

Em 1964, os professores de Alverno tiveram o Brasil como tema de estudo por todo o ano, o que incluiu o estudo da língua portuguesa. Quando Marion iniciou seus estudos de Doutorado no Teachers College, na Columbia University em Nova Iorque com Dr. Robert Pace em 1967,
2. Maria de Lourdes Junqueira Gonçalves tem sido reconhecida pela sua contribuição, na área do Piano em Grupo no Brasil, na década de 1980 . 
3. Desse estudo originou-se o livro Camargo Guarnieri: Expressóes de uma Vida publicado pela EDUSP e pela Imprensa Oficial do Estado, em 2001 ela participou como sua assistente e co-diretora da escola de Pace para crianças. Surgindo a necessidade de escolher um tópico para a produçáo de sua tese de doutorado, ela optou por estudar a música brasileira, o que lhe rendeu uma bolsa de estudos concedida pela Organização dos Estados Americanos. Ela passou, portanto, os anos de 1969 e 1970 no Brasil, estudando a música para piano solo de Francisco Mignone e Mozart Camargo Guarnieri. Ambos trabalharam com Marion Verhaalen na análise de suas próprias composiçōes ${ }^{3}$.

De volta a Milwaukee, Marion Verhaalen e Ruth Serráo, amiga brasileira e docente, colega no trabalho, organizaram um Festival de Música Brasileira contando com a visita de Guarnieri e sua esposa Vera Silvia Guarnieri. Segundo Marion Verhaalen, Guarnieri pediu para que ela intercedesse na obtenção de uma bolsa de estudos em Alverno para uma aluna brasileira dele, Cristina Capparelli. Essa solicitaçáo foi bem sucedida: Cristina realizou seus estudos no Alverno College no período de 1971-3. Durante esse tempo, Cristina deu assistência a um grupo de oito crianças, alunas de Marion, seguindo orientações da entrevistada, empregando o método de Piano em Grupo elaborado por Dr. Robert Pace. Ambas tiveram a ideia de trazer o método ao Brasil, especificamente ao Conservatório que a mãe de Cristina coordenava na cidade de Uberlândia, Minas Gerais. Esse evento foi o primeiro de muitos workshops sobre o método de Robert Pace que Marion Verhaalen ofereceu no Brasil pelos 17 anos seguintes.

Simone Gorete Machado: O que a senhora poderia relatar sobre Robert Pace?

Marion Verhaalen: O nome de Robert Pace é justamente associado a uma nova maneira de estudar piano. Em virtude de sua morte em setembro de 2010, sua filha, Dra. Cynthia Pace, escreveu:

Dr. Robert Pace é reconhecido por ter revolucionado a arte de ensinar piano nos séculos XX e XXI com suas ideias que serviram de referência tanto em conteúdo quanto em apresentação. Como educador, ele dedicou-se com entusiasmo em ajudar os alunos a se tornar aprendizes independentes e músicos para o resto da vida. Sua extraordinária visão para ensinar música por
4. Disponível em: <http:// leerobertsmusic.com/meet drpace.html/>. Data do acesso: $02 / 07 / 2015$. 
meio de ideias simples que poderiam ser infinitamente relacionadas, reformadas, e revisitadas, deixou-nos um legado duradouro - o de uma maneira de ensinar que se renova continuamente, tão dinâmica hoje quando em $1963^{4}$.

Tendo crescido em uma família musical no estado do Kansas, Dr. Pace graduou-se pela Juilliard ${ }^{5}$ e obteve mestrado e doutorado pela Teachers College, Columbia University ${ }^{6}$, ambas na cidade de Nova Iorque. Mediante pesquisa virtual, pode-se encontrar mais informaçóes disponíveis a respeito do trabalho e da biografia de Pace. A maior parte de suas atividades docentes ocorreram no Teachers College, onde ele tornou-se coordenador da área de piano em 1952 e depois assumiu a função de chefe do Departamento de Música em 1969. Ele também ocupou outros cargos de liderança na educação em nível nacional, na área de instrumentos de teclado.

SGM: Se voltássemos no tempo ainda mais, até que ponto a senhora entende que Robert Pace, enquanto aluno, aprendeu el ou foi mais influenciado na área de Piano em Grupo/Classe de Piano, por Raymond Burrows, já que Burrows era um professor ligado a esse assunto na Columbia?

MV: Robert Pace conhecia e foi inspirado pelas ideias de Raymond Burrows, além de dar crédito a Burrows pelos seus próprios esforços para desenvolver um novo modo de ensinar, baseado na interação dos alunos.

SGM: E quanto ao surgimento e crescimento do Piano em Grupo nos Estados Unidos da América, o que mais chama sua atenção?

MV: Os programas de Classes de Piano possuem uma história interessante. Essas classes poderiam ser encontradas em escolas, como por exemplo em Milwaukee, Wisconsin por volta de 1850, frequentemente com o professor tocando em um piano acústico e dezenas de alunos sentados com seu próprio teclado de papeláo. O surgimento do teclado elétrico e do piano digital, no final de 1900, trouxe um grande avanço, se esses instrumentos musicais forem comparados aos teclados de papelão. $\mathrm{O}$ que os pianos digitais inicialmente e continu-
5. The Juilliard School prioriza a educação artística voltada para a performance.

6. A maior e mais antiga instituição de pós-graduação nos EUA, prioriza a área da 
7. Nessa época, ele pertencia ao quadro de docentes da Universidade e atuava também em uma escola própria. Entretanto, atuava mais como supervisor do que como amente ofereceram com sua introduçáo, entretanto, foi uma classe de alunos que eram isolados nos seus pianos com praticamente nenhuma interaçáo entre si e nenhum contato direto com o fazer musical.

SGM: É muito comum, nos Estados Unidos da América, os professores publicarem e venderem seu próprio material didáticopedagógico a ser adotado na sala de aula. Nesse sentido, que detalhes a senhora se recorda sobre as publicaçóes de Pace?

MV: Dr. Pace publicou seu primeiro material de instrução no final de 1950. Poucos anos depois ofereceu uma revisáo, com "conteúdo" refinado em sua série Music for Piano, em 19617. Essa nova série continha livros com repertório e desenvolvimento de habilidades. Mais importante ainda, era o modo de apresentação do material didático aos alunos. Outra fonte muito rica foi a Recital Series que ele passou a publicar nos últimos 50 anos. Esse material suplementar expande e enriquece o conteúdo musical do programa. A tradução da obra Música para Piano foi realizada por Vera Silvia Guarnieri e publicada pela Ricordi em 1973. Depois de participar e serem capacitados por meio de meus workshops vários professores de piano brasileiros foram credenciados para oferecerem workshops. Alguns deles, consequentemente, têm publicado seu próprio material, assim como eu também o fiz. O curso original de Robert Pace tinha dois livros por nível. Pouco tempo depois desses livros serem publicados pela Ricordi, em versão brasileira, Pace reescreveu o programa inteiro dispondo-o em quatro livros por nível. Eu preferi não refazer essa reedição em português. Então somente existem dois níveis de Music for Piano e Skills and Drills em português. Eu também acho que meus livros Explorando Música I e II não estão mais sendo impressos pela UFRGS. Na realidade, meu livro mais recente para adultos vai muito além dos livros para crianças.

SGM: Quais caracteristicas eram tipicas de Robert Pace no modo de ensinar Piano em Grupo?

MV: Um aspecto importante e típico de seu modo de trabalhar eram os workshops estabelecidos por ele nos quais professores de piano vinham aprender e trabalhar juntos. Por meio desses workshops, que ele começou a oferecer no início de 1960, ele 
preparou centenas de professores dos Estados Unidos todo. Ele também capacitou alguns professores para oferecerem consultoria e dar assistência a treinamentos e comunicaçóes de abrangências locais. Eu fui uma dessas consultoras. Os professores aprendiam o modelo de interação que ele promovia entre os alunos na situação de aprendizado. Fabricantes de piano nos Estados Unidos apoiaram esse programa com a criação da National Piano Foundation em 1962, Fundação dirigida por Robert Pace até 1977. Depois essa Fundação Nacional de Piano internacionalizou-se. Isso contribuiu com o reconhecimento e a propagaçáo de seu programa em outros países, incluindo o Brasil em 1973.

SGM: Robert Pace veio ao Brasil em duas ocasióes, primeiro a São Paulo e depois ao Rio de Janeiro. A senhora se recorda das reaçóes de Pace sobre o Brasil? Ele ficou surpreso com algo? Ele mencionou alguma impressáo após as visitas?

MV: Eu não me recordo de nenhum comentário específico da parte dele, mas ele era tão presente às situaçóes! Ele se relacionava com as pessoas com muita facilidade e rapidamente. Eu sei que ele gostou do marido de Abigail, Claudio, ao ser entretido por ele nos intervalos das sessões. Dr. Pace divertiu-se bastante com isso.

SGM: É possivel encontrar informaçóes de que a Professora Abigail Rodrigues da Silva tenha sido uma diretora do método Robert Pace no Brasil, no periodo de 1975 a 1980, que Maria José Michalski teria sido também coordenadora do mesmo método entre os anos 1979 a 1981, e que Alice Hansen Nogueira teria se tornado a nova representante de Pace no Brasil. A senhora tem conhecimento sobre como essa coordenação e o programa de Piano em Grupo Robert Pace teriam funcionado exatamente? Houve desafios para continuá-los no Brasil?

MV: Nos Estados Unidos qualquer pessoa que participava dos workshops organizados por Dr. Pace e ensinava utilizando o método era encorajada a ajudar a desenvolver o programa. No Brasil isso também aconteceu. Não havia somente uma pessoa responsável, mas professores eram encorajados em conjunto. Durante o início do programa no Brasil foi bom nomear professores que poderiam fazer isso. $\mathrm{Na}$ realidade, depois de eles terem sido treinados, e vários terem vivido a experiência em Nova Iorque com Dr. Pace, eles tornaram-se independentes. Eu não os mantive sob vigilância, mas eu esperava que eles fossem "abrasileirar" o programa. Eu estou muito satisfeita de saber que isso tem acontecido. Com a necessidade desse tipo de pesquisa em nível universitário, o foco se expandiu para incluir alunos universitários. Entretanto, o uso de laboratórios de teclados/pianos digitais apresenta alguns desafios novos. A ênfase tem também mudado um pouco para ajudar o estudante a dominar algumas habilidades às teclas, além de somente performance de música já composta. Essa nova ênfase poderia ser um aspecto da continuação do crescimento do programa no Brasil. 


\section{Implementaçáo do Programa Pace no Brasil}

Marion Verhaalen ressalta que seu plano era oferecer workshops no Brasil para o maior número de professores possível, estabelecendo coordenadores brasileiros para "abrasileirar" o programa o mais rápido possível, encorajando alguns desses professores a ir estudar com Dr. Pace em Nova Iorque, além de trazê-lo ao Brasil para apresentar seu programa pessoalmente. Ele realmente veio a Sáo Paulo e ao Rio de Janeiro. A cronologia de workshops iniciados por Marion Verhaalen incluiu:

1973 - Uberlândia, Montes Claros, São Paulo, Goiânia, Rio de Janeiro;

1974 - Junho: Curitiba, Santos, São Paulo, Ribeirão Preto, Brasília, Porto Alegre;

1975 - Janeiro: Curitiba (Curso de Verão, de 5 semanas, no $8^{\circ}$ Festival Internacional de Música);

1976 - Janeiro: vinda de Dr. Pace com Marion Verhaalen para o primeiro Congresso do Método Pace em Sáo Paulo, organizado pela designada diretora Abigail Rodrigues Silva;

1981 - Pace veio novamente com Marion Verhaalen, dessa vez ao Conservatório Brasileiro no Rio de Janeiro;

1988 - Fevereiro a Julho: cursos de curta duração em Recife, Natal e João Pessoa durante estadia de Verhaalen em Porto Alegre, pela Fulbright;

1990 - Porto Alegre: Marion Verhaalen recebeu bolsa do National Research Council Lecture para trabalhar, por um mês, com pós-graduandos, na UFRGS.

SGM: Qual era o perfil dos participantes que geralmente compareciam aos workshops? Era composto somente de professores? Eles estavam mais relacionados ao ensino superior ou a crianças?

MV: Professores. Eu trabalhei com centenas de professores nas sessōes. E sua pergunta com relação ao público-alvo é muito importante: o objetivo era voltado ao ensino de crianças. Essa é uma grande mudança, incluindo o surgimento mais recente dos laboratórios de teclados/pianos digitais. Para uma classe, um ou dois pianos era suficiente porque as filas eram dinâmicas e mantinham todos tocando em sequência.

SGM: A senhora costuma ressaltar a importância do ensino integrado para um aprendizado conceitual. Por que acredita ser isso tão importante?

MV: O modo como um professor apresenta um conteúdo é de prioridade urgente. Estudantes deveriam saber coisas de maneiras as mais variáveis possíveis. Os vários sentidos precisam todos se inter-relacionar no processo de aprendizado: ouvidos, olhos, dedos, e consciência. O mais eficaz é uma maneira de aprendizado exploratória. A busca pela "geografia do teclado" é uma maneira vibrante de encontrar a estrutura das 88 teclas, brancas e pretas, seus nomes, suas relaçôes com o sistema tonal, escalas, 
acordes, e a relação de melodias com harmonia. A leitura de duas pautas soma-se ao desafio, tanto quanto coordenar as máos tocando notas diferentes, padróes, ritmos, e níveis de dinâmica. A memorização de tudo isso, dentro de uma estrutura rítmica com diferentes valores em cada mão, é outro desafio. Básica ainda, para se ouvir com clareza a todos esses elementos, é a técnica de quem toca. Todos esses termos - nomes de notas, escalas e acordes etc. - representam o "vocabulário" da linguagem musical, o qual precisa ser dominado para se tocar com expressividade as ideias musicais da linguagem musical. Compositores náo escrevem notas, mas eles as usam para criar ideias musicais. O que os alunos procuram conquistar é uma execução expressiva da música. E isso é somente uma introdução. Essa introdução ao piano é aprendida de maneira surpreendentemente mais rápida e eficaz em grupo do que individualmente. Aqui é onde a transformação de Class Piano para Group Piano aparece. É o ponto crucial da contribuição de Robert Pace para a área.

SGM: Para alcançar esse objetivo, que sugestôes a senhora daria para professores de piano e professores de Piano em Grupo?

MV - Para os estudantes aprenderem de uma maneira cumulativa e integrada, o professor de música deve incluir constantemente o maior número possível de sentidos em uma sucessão rápida para ajudar o aluno realmente a entender e apreender a arte de tocar. O material precisa ser apresentado em formato sequencial de modo a permitir ao estudante uma contínua expansão de seu entendimento. Uma premissa básica é: alunos nunca deveriam tocar algo que eles não entendam no seu nível. Por exemplo: se eles estáo estudando tríades maiores, eles deveriam ser capazes de descrever a formação rapidamente, localizar essas três notas rapidamente no teclado, reconhecê-las nas músicas que estão tocando, entender a relação desse acorde com as melodias sendo harmonizadas, usá-los em improvisaçóes originais etc. Em um grupo, um estudante pode descrever a formação do acorde rapidamente, outro pode escrevê-lo mais rápido, um terceiro pode saber usá-lo com mais facilidade. E assim eles podem aprender entre $s i$, se o professor incorporar todos os aspectos do aprendizado. A riqueza de diferentes facilidades de cada aluno acrescenta ao ambiente de aprendizado. E quando uma base é cuidadosamente preparada a cada semana, iniciantes começam a pensar como músicos, que é um objetivo almejado por todos envolvidos. São inúmeros os exemplos de como crianças internalizam esse tipo de ensino. Um procedimento cumulativo também é muito atraente para adultos que querem retornar ao piano. Adultos trazem na memória várias lembranças de músicas, e eles gostariam de ver o resultado pronto em pouco tempo. Eles ficam animados com o desafio de aprender as inter-relaçóes de tudo que é envolvido ao tocá-las. Alguns sabem ler somente uma clave em outro instrumento, portanto eles trazem tanto seus pontos fortes quanto as lacunas, do seu 
aprendizado prévio. Um professor alerta irá aprender como utilizar o talento de cada pessoa em um grupo.

\section{SGM: A senhora vê equivocos no Piano em Grupo atualmente?}

MV: O desafio de hoje parece ser o de renascer o objetivo do ensino de uma maneira integrada. Ter estudantes sentados a pianos digitais com fones de ouvido, esperando pelo professor para ouvir sua peça solo pode até ser Class Piano mas náo é Group Piano. O recurso que parece ser muito útil é o de começar constantemente cada aula e momento de estudo com atenção ao "vocabulário musical" a ser usado. Enfatizar a importância de estar familiarizado, primeiro com: o padrão de escalas maiores com as primeiras 5 notas, incluindo as tríades em que elas se baseiam, ou escalas maiores de 8 notas, ou tríades maiores com inversóes, padróes similares de tríades ao teclado etc. Os alunos precisam ter facilidade com esses elementos básicos. Somente assim os símbolos podem funcionar como linguagem musical. Tocar em conjunto também propicia recompensas ao desenvolver um bom senso de ritmo e pulso. Deve-se saber o conteúdo musical tanto quanto se sabe o próprio nome, levar três segundos para responder uma simples pergunta ou comando é tempo demais. Nesse caso, testar o grupo em conjunto pode acelerar o momento e a precisão de suas respostas. Se você, como professor, sente entusiasmo nesse procedimento, a sugestão é: persiga-o! Isso é o que Cynthia Pace se referia no texto sobre seu pai, onde ela escreveu: "Sua visão extraordinária para ensinar música por meio de ideias simples poderia ser infinitamente inter-relacionada, reformulada e revisitada e deixou uma herança duradoura - a de uma metodologia de auto-renovação contínua."

SGM: Qual é a sua impressão sobre o estágio que o Piano em Grupo apresenta hoje, no Brasil?

MV: O que tem sido desenvolvido, no Brasil, na área do Piano em Grupo, desde a sua introdução em 1973 (40 anos atrás!) é maravilhoso. Que essa maneira de ensinar e aprender tenha ficado profundamente arraigada nesse país táo musical, deve-se aos milhares de professores que implementaram-na no passado, e a todos aqueles que tem continuado a trabalhar com essa maneira critativa de aprender música por meio do teclado. Eu estou muito satisfeita em ver os frutos daqueles esforços iniciais, incluindo os materiais que muitos professores brasileiros têm criado e disponibilizado aos estudantes. Quando alunos e professores trabalham juntos em colaboração integrada, o resultado só pode ser benéfico. Eu estou grata pelo trabalho de todos vocês, que é ótimo!! 


\section{Consideraçóes Finais}

Agradecemos à professora entrevistada, por sua abertura para o debate sobre estudos de Piano em Grupo, no Brasil. Suas contribuiçóes nos permitiram conhecer um pouco mais sobre a metodologia de Robert Pace e sobre a introdução dessa modalidade de ensino de música no país. De acordo com Christopher Fisher, em seu livro Teaching Piano in Groups (2010), trata-se de metodologia cumulativa, que incluía a aplicação dos elementos musicais básicos em várias tonalidades, harmonia, treino auditivo, leitura e improvisação, e que foi publicada nos EUA, inicialmente no livro didático Piano for Classroom Music, em 1956. Entretanto, Marion Verhaalen alerta que esse livro foi um esforço de Robert Pace para contribuir com os professores de escolas regulares no ensino de teoria musical para complementar as atividades musicais já inerentes ao currículo destas escolas e que não deve ser inserido na categoria de Piano em Grupo.

Duas outras obras foram produzidas posteriormente e ambas ampliaram e aperfeiçoaram essa metodologia para Piano em Grupo sendo planejados como complementares entre si: Music for Piano (1961) e Skills and Drills (1961). Essas publicaçôes foram traduzidas para o português, mas não são acompanhadas por um livro destinado ao professor, embora a contra-capa apresente sugestóes breves para utilizaçáo do material exposto pelo autor. Destacamos que o livro 1 de Música para Piano, por exemplo, contém pouco texto explicativo mas vários exemplos musicais. A maneira de serem aplicados em sala de aula, segundo a metodologia de Pace, para Piano em Grupo, era, na época, demonstrada prioritariamente em workshops.

Vera Silvia Camargo Guarnieri e Marion Verhaalen foram responsáveis pela tradução e adaptação da obra em referência para o português. Música para Piano (livro 1) foi publicado pela Ricordi Brasileira S/A, em 1973. Trata-se de um volume que pressupóe interaçáo com o outro livro do autor, em que se somam mais exercícios teóricos destinados ao desenvolvimento de habilidades musicais propostas pelo programa de estudo ao piano. Esse livro de exercícios teóricos Skills and Drills que acompanha Música para Piano recebeu o título de Criando e 
8 Professora do Departamento de Música (FFCLRP-USP).
Aprendendo, sendo publicado também pela Ricordi em 1973, traduzido e adaptado pelas mesmas autoras.

Entretanto, acreditamos ser importante esclarecer que se trata de uma série: o primeiro exemplar, tanto de Música para Piano, quanto de Criando e Aprendendo, apresenta a classificação de Livro 1 na capa, mas também de Volume 1 no interior do livro. Pudemos encontrar ainda alguns exemplares em português com a classificaçáo de Livro/Volume 2, 3 e 4, embora, nesses últimos, não tenhamos encontrado indicação de nível, além da ausência do ano de publicação. Essas obras estão esgotadas. Atualmente, o trabalho de Robert Pace, publicado no idioma original, pode ser adquirido por meio da página virtual da editora Lee Roberts Music Publications, ou por intermédio da página virtual da distribuidora Hal Leonard Corporation.

Simone Gorete Machado ${ }^{8}$ 